\title{
Rock-magnetic properties of single zircon crystals sampled from the Tanzawa tonalitic pluton, central Japan
}

\author{
Masahiko Sato ${ }^{1,2^{*}}$, Shinji Yamamoto ${ }^{3}$, Yuhji Yamamoto ${ }^{4}$, Yoshihiro Okada ${ }^{5}$, Masao Ohno ${ }^{2}$, Hideo Tsunakawa ${ }^{5}$
} and Shigenori Maruyama ${ }^{6}$

\begin{abstract}
This paper reports on the rock-magnetic properties of single zircon crystals, which are essential for future work establishing the reliable paleointensity method using single zircon crystals. Zircon crystals used in this study were sampled from the Nakagawa River, which crosses the Tanzawa tonalitic pluton in central Japan. Rock-magnetic measurements were conducted on 1037 grains of zircons, but many of these measurements are below the limits of the sensitivity of the magnetometers employed. Isothermal remanent magnetizations (IRMs) of 876 zircon crystal are below the practical resolution of this study; we infer that these crystals contain no or only minute quantities of ferromagnetic minerals. The other zircon crystals contain enough magnetic minerals to be measured in the DC SQUID magnetometer. For 81 zircon crystals, IRM intensities $\left(M_{\mathrm{IRM}}\right)$ are larger than $4 \times 10^{-12} \mathrm{Am}^{2}$, while natural remanent magnetization (NRM) intensities ( $M_{\text {NRM }}$ ) are below $4 \times 10^{-12} \mathrm{Am}^{2}$, indicating that these crystals are inappropriate for the paleomagnetic study. For the samples that had values of $M_{\mathrm{NRM}} \geq 4 \times 10^{-12} \mathrm{Am}^{2}$ and $M_{\mathrm{IRM}} \geq 4 \times 10^{-12} \mathrm{Am}^{2}$ (80 zircons), combining the rock-magnetic parameter, we proposed the sample-selection criteria for future study of paleointensity experiments using single zircon crystals. In the case that the samples had high coercivity $\left(B_{c}\right)$ values $(>10 \mathrm{mT})$ or high $M_{\text {NRM }} / M_{\text {IRM }}$ values (> 0.1), main remanence carriers are probably pyrrhotite and these samples are inappropriate for the paleointensity study. In the case that the samples had low $B_{c}$ values $(<10 \mathrm{mT})$ and low $M_{N R M} / M_{\mathbb{R M M}}$ values $(<\sim 0.1)$, main remanence carriers seem to be nearly pure magnetite with pseudo-single-domain grain sizes, and these samples are expected to appropriate for the paleointensity study. Total thermoremanent magnetization (TRM) acquisition experiments were also carried out for 12 samples satisfying the above criteria. The TRM intensity was comparable with that of NRM, and a rough estimation of the paleointensity using NRM/TRM ratios shows field intensities consistent with the average geomagnetic field intensity at the Tanzawa tonalitic pluton for last $5 \mathrm{Myr}$.
\end{abstract}

Keywords: Rock-magnetism; Paleointensity; Zircon; Tanzawa tonalitic pluton

\section{Findings Introduction}

Geomagnetic field paleointensity data provide critical information about the thermal evolution of the Earth, and the state of the geomagnetic field has been proposed to be closely related to the surface environment (Tarduno et al. 2014). While it is pivotal to understand the variations in geomagnetic field intensity through the history of the

\footnotetext{
* Correspondence: m.satou@aist.go.jp

'Geological Survey of Japan, National Institute of Advanced Industrial Science and Technology, 1-1-1 Higashi, Tsukuba 305-8567, Japan ${ }^{2}$ Department of Environmental Changes, Faculty of Social and Cultural Studies, Kyushu University, 744 Motooka, Nishi-ku, Fukuoka 819-0395, Japan Full list of author information is available at the end of the article
}

Earth, data are still too scarce to a resolve billion-yearscale geomagnetic field variation. This is primarily due to the lack of well-preserved rocks for older eras, which often results in unsuccessful paleointensity experiments.

To overcome this problem, much research in recent years has focused on paleointensity experiments using single silicate crystals, which often accompany magnetic mineral inclusions, such as plagioclase (Tarduno et al. 2006 and references therein), quartz phenocryst (Tarduno et al. 2010), pyroxene (Muxworthy and Evans 2012), and olivine (Tarduno et al. 2012). Notably, the paleointensity method using single silicate crystals can be applied to the samples that failed paleointensity experiments using bulk

\section{它 Springer}


rock to obtain new, valuable information. However, some crystal types, such as plagioclase, pyroxene, and olivine, are easily influenced by alteration and metamorphism, and paleointensity experiments are still limited to the small number of samples.

This study focuses on zircon crystals. Zircon crystals play an important role in paleomagnetic studies because they have several mineralogical advantages: (1) they commonly occur in crustal rocks, (2) precise age determinations with $\mathrm{U}-\mathrm{Th}-\mathrm{Pb}$ and (U-Th)/He analyses are possible, and (3) they are highly resilient and may provide our only means to examine the oldest geomagnetic field (Tarduno et al., 2014, 2015). Recently Tarduno et al. (2015) demonstrated that paleointensity data of Archean to Hedean zircons bearing magnetic inclusions from the Jack Hills conglomerate could be used to reconstruct the early geodynamo. Although rock-magnetic properties of single zircon crystal are essential for future work establishing the reliable paleointensity method, systematic rock-magnetic studies have not been conducted for single zircon crystals, which is largely because of their small size and related weak magnetic moment.

This study conducts systematic rock-magnetic measurements using single zircon crystals that originated from the Tanzawa tonalite in central Japan. The materials in this region represent typical continental crust. Moreover, the crystals have young crystallization ages and a clear thermal history. We report the rock-magnetic properties of zircon crystals, and a preliminary result of thermoremanent magnetization (TRM) acquisition experiment for future study of paleointensity experiments using single zircon crystals.

\section{Geology and sampling}

Zircon crystals used in this study were sampled from fluvial sands of the Nakagawa River, which crosses the Tanzawa tonalitic plutons in central Japan ( $35^{\circ} 26^{\prime} 05^{\prime \prime}$ $\mathrm{N}, 139^{\circ} 02^{\prime} 44^{\prime \prime}$ E). A geological map around the Tanzawa block and Nakawaga River is shown in Fig. 1a. The Tanzawa block is situated in the Izu Collision Zone, where the Izu-Bonin-Mariana (IBM) arc has collided with the Honshu arc (Matsuda 1978; Niitsuma et al. 2003; Yamamoto et al. 2009). The IBM arc is believed to be the major site of continental crust formation. The seismic profiling of the IBM arc crust demonstrated the presence of a middle crust with the $\mathrm{P}$ wave velocity $\left(V_{\mathrm{p}}\right)$ of $6 \mathrm{~km} / \mathrm{s}$ (Suyehiro et al. 1996; Takahashi et al. 2007). The $V_{\mathrm{p}}$ value corresponded to intermediate-tofelsic tonalitic composition, which is average chemical composition of the continental crust (e.g., Rudnick et al., 1995). The Tanzawa block is divided into three main geological units: (1) the Tanzawa Group (basaltic volcanoclastics), (2) the Tanzawa gabbro suite, and (3) the Tanzawa tonalitic plutons. According to previous studies, the Tanzawa tonalities can be regarded as the exposed middle crust of the former IBM arc (Suyehiro et al. 1996; Kawate and Arima 1998), and thus, the Tanzawa tonalitic pluton is generally considered to be a typical continental crust. The Tanzawa tonalities have very low $\mathrm{K}_{2} \mathrm{O}$, low $\mathrm{K}_{2} \mathrm{O} / \mathrm{Na}_{2} \mathrm{O}$ ratios (Ishihara et al. 1976), and low initial ${ }^{87} \mathrm{Sr} /{ }^{86} \mathrm{Sr}$ ratios near mantle values (Kawate and Fujimaki 1996; Tamura et al. 2010); they are also enriched in magnetite with high magnetic susceptibility (Ishihara et al. 1976; Ishihara and Matsuhisa 1999).
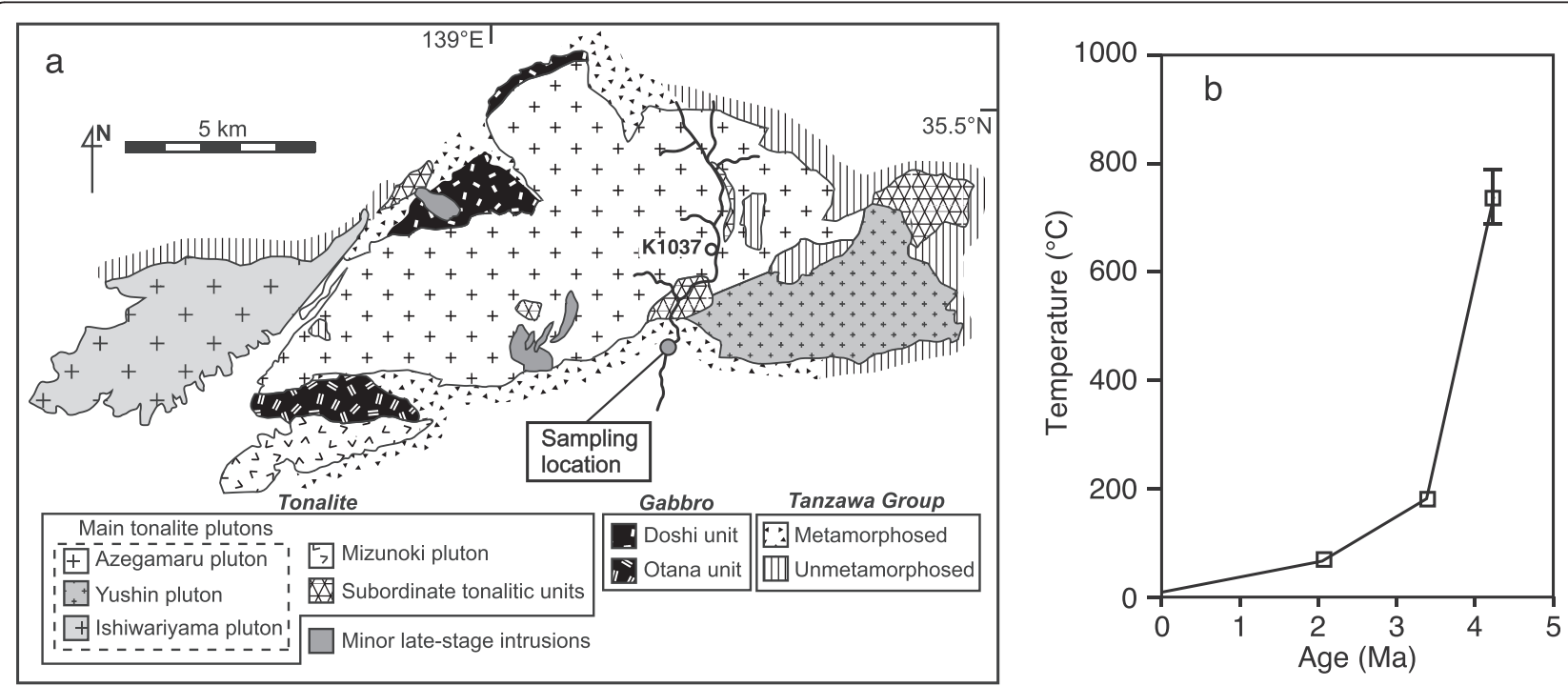

Fig. 1 Geological data of the Tanzawa plutonic complex (modified after Tani et al. 2010). a Geological map and b cooling path of the Azegamaru pluton. K1037 indicates the point where the temperature versus age data were obtained (Yamada and Tagami 2008; Tani et al. 2010) 
The Nakagawa River flows along bodies of the Tanzawa plutonic complex. Since the fluvial sands were collected just downstream of the Azegamaru pluton (Fig. 1a), we can collect large amounts of coarse-grained zircon crystals that had originated from the Azegamaru pluton. Note that the zircon crystal collected at the point may contain a certain amount of zircon crystals that had originated from the subordinate tonalitic unit (Otakisawa unit). The Otakisawa unit formed between the Gabbroic unit and the Azegamaru pluton (Takita 1974). The zircon $\mathrm{U}-\mathrm{Pb}$ ages in the Gabbroic unit were determined as ca. 5 Ma (Tani et al. 2010). The typical grain size of the Tanzawa zircon ranges from 50 to $200 \mu \mathrm{m}$ (Suzuki et al. 2014), and we selectively collected coarse zircon crystals larger than $150 \mu \mathrm{m}$ in size.

The zircon $\mathrm{U}-\mathrm{Pb}$ ages in the Azegamaru pluton were determined as ca. 4-5 Ma using a sensitive high resolution ion micro probe and laser ablation-inductively coupled plasma mass spectrometry (Tani et al. 2010; Suzuki et al. 2014). Yamada and Tagami (2008) also reported (U-Th)/He zircon and apatite ages. On the basis of these results, post emplacement thermal history of the Azegamaru pluton can be estimated. The cooling rate of the Azegamaru pluton was calculated to be $\sim 658{ }^{\circ} \mathrm{C} / \mathrm{Myr}$ during the time span of 3-4 Ma (Fig. 1b), and Tani et al. (2010) pointed out that the Tanzawa plutonic complex is one of the most rapidly cooled granitic plutons on the Earth. It is worth noting that the Azegamaru pluton did not experience severe heating after the rapid cooling (Fig. 1b). The young crystallization ages and the clear thermal history make the Azegamaru pluton suitable for testing the feasibility of conducting a paleointensity experiment using single zircon crystals.

\section{Methods \\ Zircon preparations}

Heavy mineral fractions including zircon grains were concentrated from fluvial sands of the Nakagawa River using a panning method without magneticseparation and heavy-liquid techniques to avoid any adverse effects on magnetic measurements. Later, the heavy fractions were sieved and arranged so that the samples were larger than $150 \mu \mathrm{m}$ in size. Finally, zircon grains were hand-picked at random under a stereoscopic microscope for further analyses.

We collected 56 grains of zircon crystals to conduct a hydrochloric acid $(\mathrm{HCl})$ leaching experiment. First, the 56 grains were placed together using a Scotch Magic Transparent Tape (3 M) and isothermal remanent magnetization (IRM) was imparted with a field of $140 \mathrm{mT}$. The IRM intensity $\left(M_{\text {IRM }}\right)$ of the 56 crystals was then measured using a $2 \mathrm{G}$ 3-component DC SQUID magnetometer (model 755) at Kyushu University.
Subsequently, the zircon crystals were removed from the tape and soaked in $\mathrm{HCl}$ for 4 to $8 \mathrm{~d}$ ( $\mathrm{HCl}$ leaching), and then, the crystals were washed with water. The 56 grains were placed together using the tape. The IRM was again imparted for the 56 crystals, and $M_{\text {IRM }}$ was measured.

For the main series of magnetic measurements, 1037 grains of zircon crystals were collected and used after $\mathrm{HCl}$ leaching for $10 \mathrm{~d}$. To characterize the zircon, X-ray fluorescence (XRF) measurements were conducted on the 1037 grains with $\mathrm{X}$-ray spot sizes of $100 \mu \mathrm{m}$ using an XGT-7000 X-ray Analytical Microscope (HORIBA Scientific) at Kyoto University. Note that XRF observations were conducted after natural remanent magnetization (NRM) measurements.

\section{Remanence measurement using SQUID magnetometer}

Remanence measurements were carried out using a 2G 3component DC SQUID magnetometer (model 755-4.2 cm discrete sample system) at the Center for Advanced Marine Core Research (CMCR), Kochi University. We used a sample holder specially designed for zircon measurements. The holder was made of acrylonitrile butadiene styrene (ABS) and cylindrical form of $7 \mathrm{~mm}$ in diameter and $6 \mathrm{~cm}$ in length (Additional file 1: Figure S1). The sample holder was fixed in a stainless rod and inserted into a sensing region of the magnetometer. The zircon crystal was sandwiched between the two Scotch Magic Transparent Tapes of $5 \times$ $5 \mathrm{~mm}$ (sandwiched sample) and set at an edge of the holder using the Scotch Double Sided Tape (3 M). To keep a sample orientation, we fixed the zircon crystal sandwiched between the Transparent Tapes from NRM measurement to end of demagnetization/remanence measurement processes. In a sequence of remanence measurements, the sample holder was fixed in the stainless rod, and we only changed the sandwiched sample at an edge of the holder.

The typical sample holder moment with the Double Sided Tape was $\sim 3 \times 10^{-11} \mathrm{Am}^{2}$, and specific axis of the magnetometer did not show larger noise. To calculate the sample moment, we subtracted the holder magnetization from each sample measurement. We carried out repeated measurements of the holder to estimate the detection limit of our method. The holder moment after subtracting the averaged holder moment showed variation of $\sim 2 \times 10^{-12} \mathrm{Am}^{2}$ (Additional file 1: Figure S2). Thus, the practical detection limit of sample moments in our method was estimated to be $\sim 4 \times 10^{-12} \mathrm{Am}^{2}$.

\section{NRM and IRM measurements}

For 1037 grains of zircon crystals, NRM intensity $\left(M_{\mathrm{NRM}}\right)$ was first measured. Then, IRM was imparted with a field of $1 \mathrm{~T}$ using pulse magnetizers (ASC Scientific IM-10-30 Impulse Magnetizer and Magnetic Measurements PPMP10), and the resultant IRM intensity 
was measured. Note that the IRMs were imparted for $\sim 70$ samples at one time and were roughly imparted to the north direction. For 142 grains with $M_{\text {IRM }}$ values larger than $5 \times 10^{-12} \mathrm{Am}^{2}$, low-temperature demagnetization (LTD) treatment was further conducted, and the memory (IRM intensity after LTD treatment; $M_{\text {IRM-LTD }}$ ) was measured. In this treatment, the sandwiched sample was placed in a Dewar bottle filled with liquid nitrogen and equilibrated for $1 \mathrm{~min}$. Then, the sample was kept at room temperature for $2 \mathrm{~min}$.

\section{Hysteresis loop measurements}

Magnetic hysteresis loops were measured for 46 zircon crystals with $M_{\text {IRM }} \geq 1 \times 10^{-10} \mathrm{Am}^{2}$ and $M_{\mathrm{NRM}} \geq$ $4 \times 10^{-12} \mathrm{Am}^{2}$ using a MicroMag 2900 Alternating Gradient Magnetometer (Princeton Measurements Corporation) at Kyushu University. We used a P2 AGM transducer probe with a silica sample stage (Princeton Measurements Corporation). A saturation magnetization $\left(M_{\mathrm{s}}\right)$ of the probe was typically $\sim 100 \mathrm{pAm}^{2}$ (Additional file 1: Figure S3). Prior to the zircon sample measurements, a hysteresis loop of the probe was measured to obtain data for a probe correction. In the zircon measurements, the hysteresis loop of the probe was subtracted from the measured hysteresis loop (probe + zircon sample) to calculate the magnetization of the zircon sample. The maximum field in the hysteresis loop measurement was $500 \mathrm{mT}$. For characterizations of the hysteresis parameters, a diamagnetic/paramagnetic correction was performed by subtracting the average slopes at the applied field of $|B|>300 \mathrm{mT}$. Coercivity $\left(B_{\mathrm{c}}\right)$ was determined by a second-degree polynomial interpolation. $M_{\mathrm{s}}$ was the average of the magnetizations for $|B|>300 \mathrm{mT}$.

\section{Stepwise alternating field demagnetization and low-temperature magnetometry}

To further investigate the magnetic properties of the zircon crystals, stepwise alternating field demagnetization (AFD) experiment and low-temperature remanence measurements were carried out for 12 zircon crystals. We prepared four sets of samples, which had $M_{\mathrm{NRM}} / M_{\text {IRM }}$ values of $\sim 0.01, \sim 0.05, \sim 0.1$, and $\sim 1$. For the 12 zircon crystals, the stepwise AFD were carried out on 1 T-IRMs after the LTD treatment with steps at $2,4,6,8,10,12,14,16,18,20$, $22.5,25,27.5,30,35,40$, and $45 \mathrm{mT}$. The AFD was performed using a DEM-95C alternating field demagnetizer (Natsuhara-Giken) with the two-axis tumbling system. Subsequently, using an MPMS-XL5 Magnetic Property Measurement System (Quantum Design) at CMCR, Kochi University, low-temperature remanence measurements were conducted for the 12 grains. This involved (1) thermal demagnetization during zero-field warming (ZFW) for an IRM imparted with a field of $2.5 \mathrm{~T}$ at $10 \mathrm{~K}$ after zero-field cooling from $300 \mathrm{~K}$ (ZFC remanence) and (2) thermal demagnetization during ZFW for a remanence given by field cooling from 300 to $10 \mathrm{~K}$ with a field of $2.5 \mathrm{~T}$ (FC remanence).

\section{Results}

\section{Zircon preparation}

Representative photo images of the zircon crystals are shown in Fig. 2. It can be seen that the crystals have stubby euhedral shapes with colorless or pale pink, which are common characteristics of Tanzawa tonalities (Tani et al. 2010; Suzuki et al. 2014). All the crystals used in the magnetic measurements also showed a clear peak for zirconium in the XRF measurements. It was concluded that the 1037 crystals can be classified as zircons based on the stereoscopic microscope and XRF observations.

The IRM intensity decreased during $\mathrm{HCl}$ leaching for $4 \mathrm{~d}$ and was nearly constant after $4 \mathrm{~d}$ (Additional file 1 : Figure S4). It is thought that surficial contamination of magnetic minerals can be removed by $\mathrm{HCl}$ leaching for 4 d, as previously reported by Lewis and Senftle (1966). Our main series of experiments were conducted on 1037 grains of zircon crystals that were subjected to $\mathrm{HCl}$ leaching for $10 \mathrm{~d}$, thus they were most likely not affected by any surficial contamination.

\section{NRM, IRM measurements}

Results of the NRM and IRM measurements are shown in Fig. 3. Although the NRM intensity of the single zircon crystals varied from $10^{-13}$ to $10^{-9} \mathrm{Am}^{2}$, the practical detection limit of sample moments was $\sim 4 \times 10^{-12} \mathrm{Am}^{2}$, and the cluster of points below the limit is an artifact of magnetometer resolution rather than any special characteristic of the zircons. For 85 crystals (8.2 \%), NRM intensities were larger than $4 \times 10^{-12} \mathrm{Am}^{2}$. The IRM intensities of the single zircon crystals also varied by four orders of magnitude, and 161 crystals (15.5\%) had IRM intensity larger than $4 \times 10^{-12} \mathrm{Am}^{2}$.

The LTD memory of IRM $\left(100 \times M_{\text {IRM-LTD }} / M_{\text {IRM }}\right)$ is plotted as a function of IRM intensity in Fig. 4a. A portion of the samples with $M_{\text {IRM }}$ values less than $1 \times$ $10^{-11} \mathrm{Am}^{2}$ showed a LTD memory of IRM that was larger than $100 \%$, which was due to measurement errors. For the samples with values of $M_{\text {IRM }} \geq 1 \times 10^{-11} \mathrm{Am}^{2}$, there was no clear correlation between the $M_{\mathrm{IRM}}$ and $100 \times M_{\text {IRM-LTD }} / M_{\text {IRM }}$ (correlation coefficient approximately -0.22). The LTD memories of IRM were mainly distributed in the range of 50-70 \% (Fig. 4b). The decrease in the IRM intensity after LTD treatment suggests the existence of nearly pure magnetite (Heider et al. 1992).

\section{Hysteresis loop measurements}

Typical examples of the magnetic hysteresis loops before and after slope correction are shown in Fig. 5a-d. 
(a) TNZ03-06-19

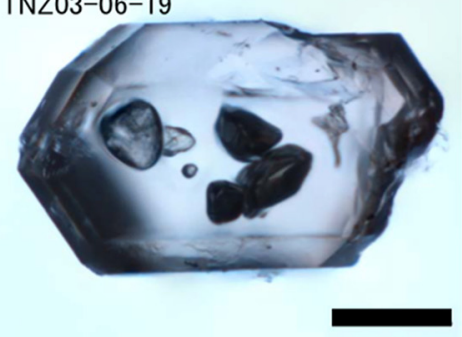

(d) TNZ03-01-37

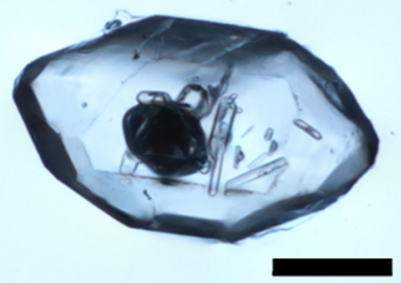

(g) TNZ03-08-41

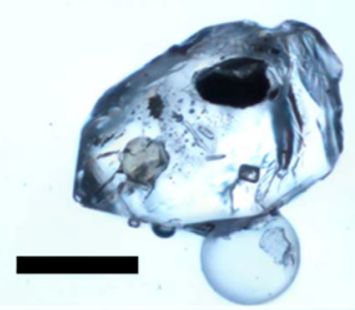

(j) TNZ03-08-07
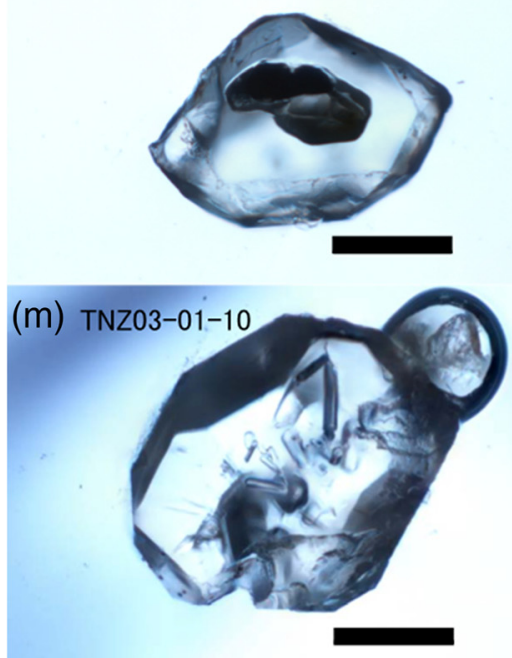

(b) TNZ03-06-42

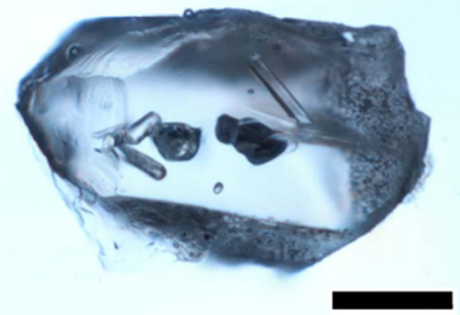

(e) TNZ03-09-12

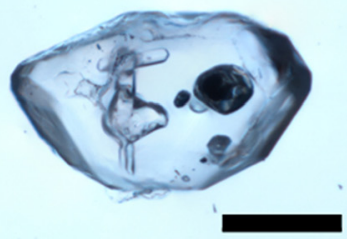

(c) TNZ03-14-62

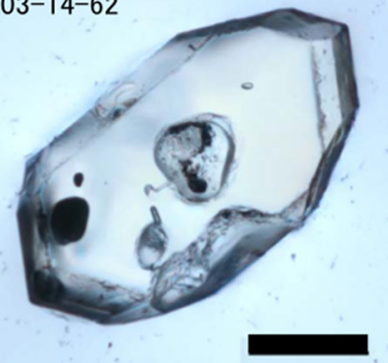

(f) TNZ03-09-49

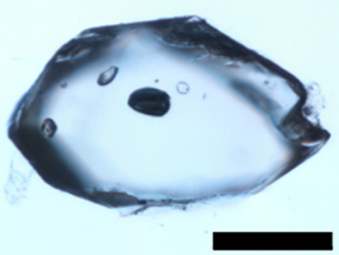

(h) TNZ03-03-23

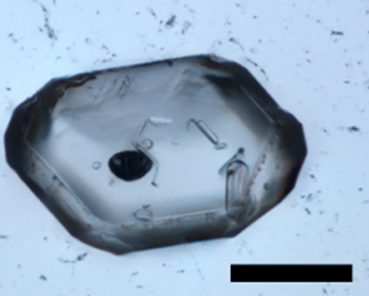

(k) TNZ03-04-65

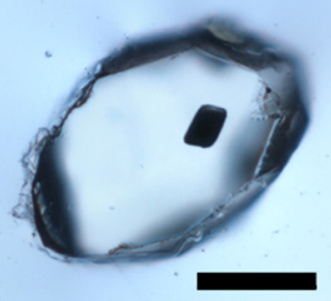

(n) TNZ03-01-44

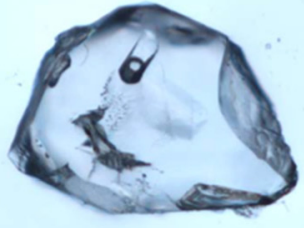

(i) TNZO3-03-40

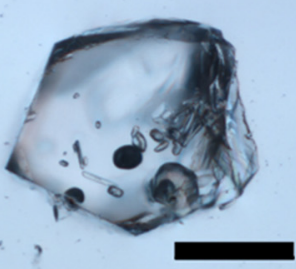

(I) TNZO3-15-57

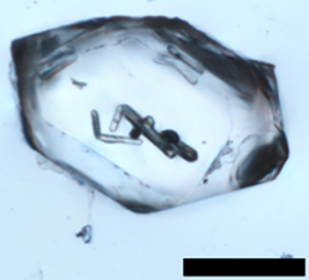

(0) TNZO3-03-30

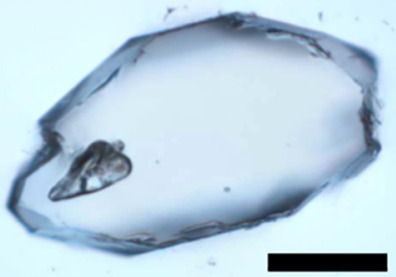

Fig. 2 Photo images of zircon crystals. The images are composite image of several photos which were taken at different depth of focus. Scale bars are $100 \mu \mathrm{m}$. The $M_{\text {NRM }} / M_{\text {IRM }}$ values are $\mathbf{a}-\mathbf{c} \sim 0.01, \mathbf{d}-\mathbf{f} \sim 0.05, \mathbf{g}-\mathbf{i} \sim 0.1$, and $\mathbf{j}-\mathbf{I} \sim 1 . \mathbf{m}-\mathbf{o}$ The $M_{\mathbb{R} M}$ values are lower than the detection limit (see text) 

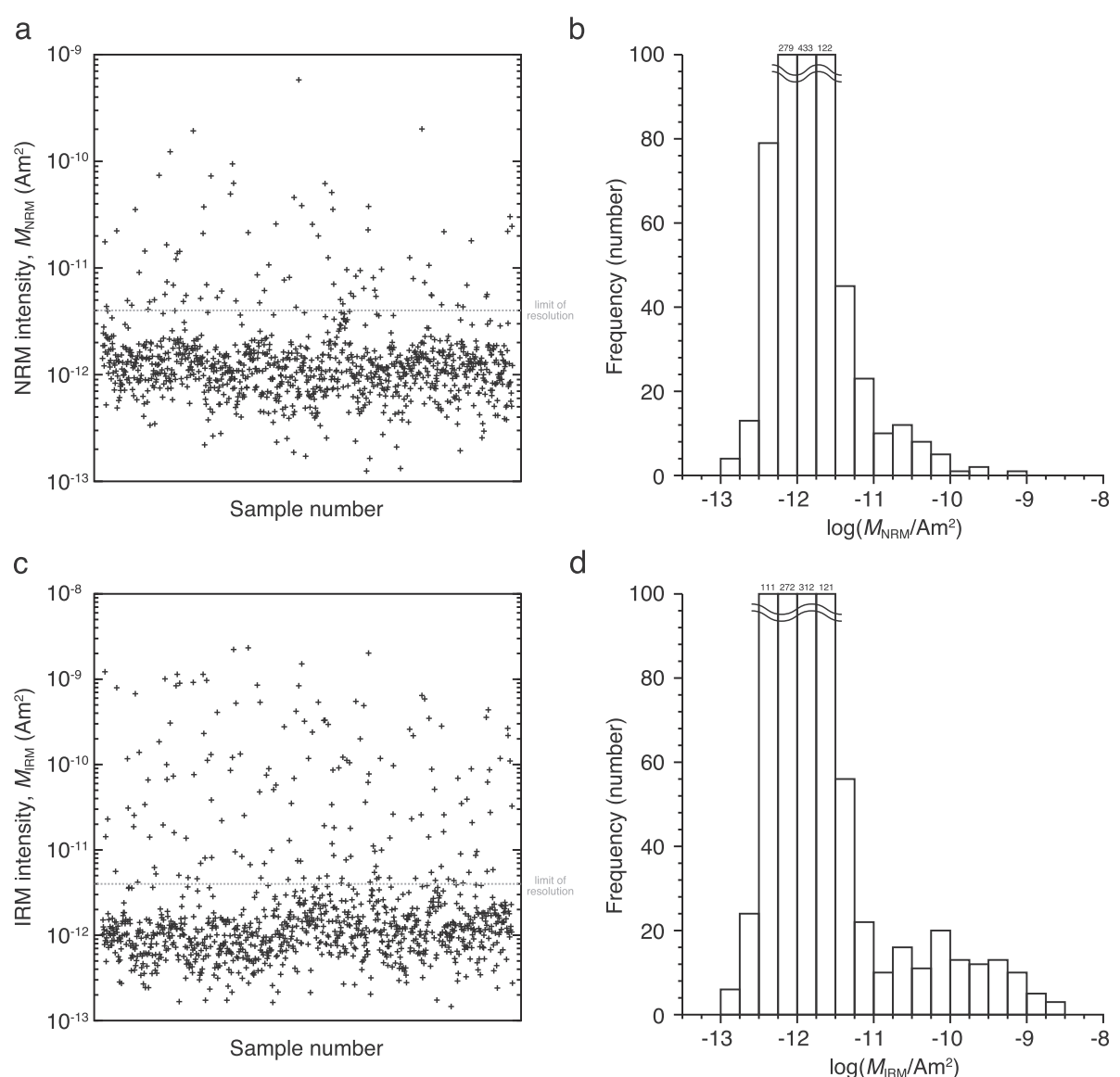

Fig. 3 Results of the NRM and IRM measurements. a NRM intensity, $\mathbf{b}$ histogram of NRM intensity, $\mathbf{c}$ IRM intensity, and $\mathbf{d}$ histogram of IRM intensity. The detection limit of sample moments is indicated as grey line

In order to evaluate the precision of the measurements, we calculated the standard deviation of $M_{\mathrm{s}}\left(\sigma_{\mathrm{Ms}}\right)$ for $|B|>300 \mathrm{mT}$. The $\sigma_{\mathrm{Ms}}$ values were calculated to be $\sim 100 \mathrm{pAm}^{2}$ for all samples. Because the $M_{\mathrm{s}}$ values should be constant in the hysteresis measurements, it is reasonable to consider that the induced magnetizations can be measured with $\sim 100 \mathrm{pAm}^{2}$ precisions. The standard errors of $M_{\mathrm{s}}\left(\delta_{\mathrm{Ms}}\right)$ were calculated to be $\sim 5 \mathrm{pAm}^{2}$ because of the stacking of $\sim 400$ points in $M_{\mathrm{s}}$ calculation. Thus, signal to noise ratios for $M_{\mathrm{s}}$ that
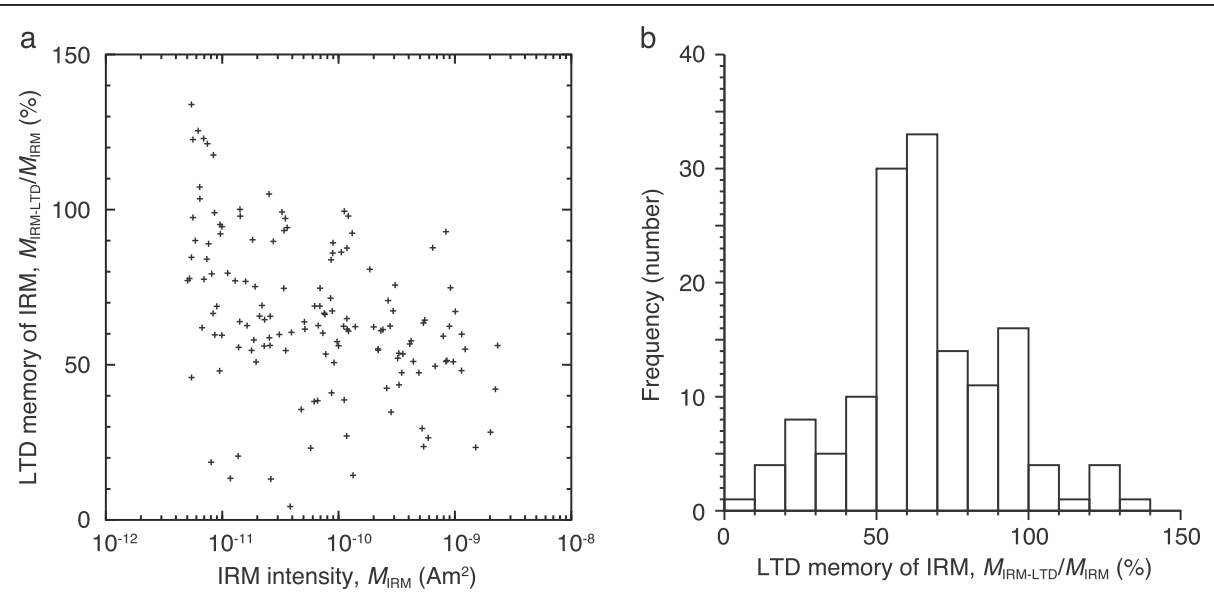

Fig. 4 Results of the LTD treatments for IRM. a The LTD memory of IRM is plotted as a function of IRM intensity. b Histogram of LTD memory of IRM 

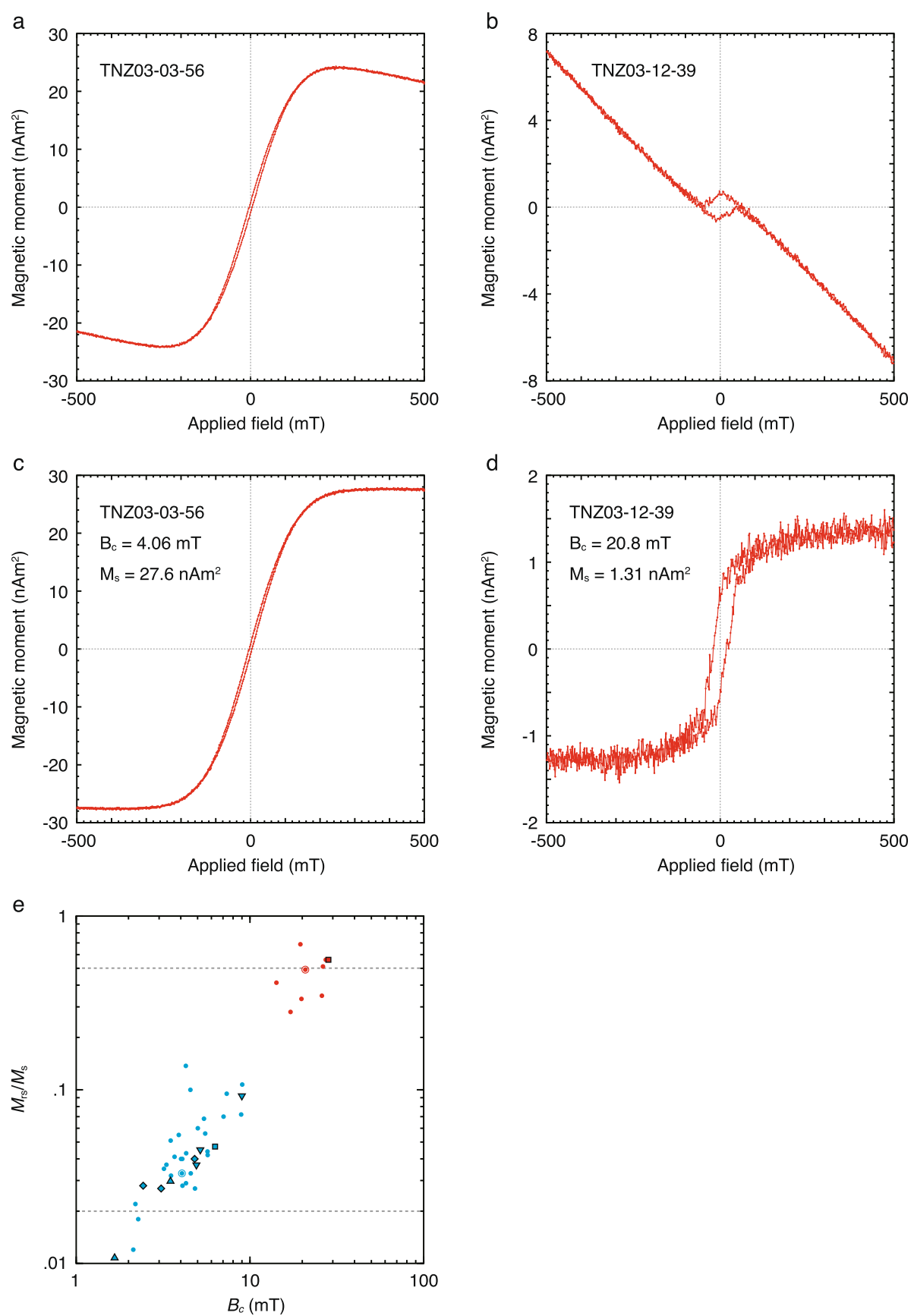

Fig. 5 Results of magnetic hysteresis measurements. a-d Examples of the hysteresis loops. The SD-like sample $\mathbf{a}$ before and $\mathbf{c}$ after the diamagnetic/ paramagnetic correction. The PSD-like sample $\mathbf{b}$ before and $\mathbf{d}$ after the diamagnetic/paramagnetic correction. $\mathbf{e} T$ The $M_{r s} / M_{s}$ is plotted as a function of $B_{c}$. Grey lines indicate $M_{r s} / M_{s}$ values of 0.5 and 0.02, which are representative values for SD/PSD and PSD/MD boundaries (Dunlop 2002). Data from the hysteresis loops in $\mathbf{c}$ and $\mathbf{d}$ are shown as double circles. The selected samples are shown as inverted triangle, diamond, triangle, and square symbols (see Fig. 6)

based on the $\delta_{\mathrm{Ms}}$ values relative to the sample $M_{\mathrm{s}}$ ranged from 46 to 12,000 . The $B_{\mathrm{c}}$ values varied from 1 to $30 \mathrm{mT}$, and the standard errors for $B_{\mathrm{c}}$ calculated from the second-degree polynomial fitting were typically 10\% (Additional file 1: Tables S1 and S2). Since the $B_{\mathrm{c}}$ values for all samples were lower than $30 \mathrm{mT}$, it is reasonable to consider that the IRM imparted with a field of $1 \mathrm{~T}$ is close to the saturation IRM (SIRM). For most of the samples, the noise of $\sim 100 \mathrm{pAm}^{2}$ was too large to estimate a saturation remanent magnetization $\left(M_{\mathrm{rs}}\right)$. To precisely calculate the $M_{\mathrm{rs}} / M_{\mathrm{s}}$ ratio, the $M_{\text {IRM }}$ obtained from the IRM measurements was used as the $M_{\mathrm{rs}}$ value.

The magnetic hysteresis parameters of the single zircon crystals are plotted over the $M_{\mathrm{rs}} / M_{\mathrm{s}}$ versus $B_{c}$ plots (Tauxe 
et al. 2002) in Fig. 5e. Representative $M_{\mathrm{rs}} / M_{\mathrm{s}}$ values for single-domain (SD)/pseudo-single-domain (PSD) and PSD/ multidomain (MD) boundaries in the plots by Day et al. (1977) are also shown in Fig. 5e (Dunlop 2002). The SD- and PSD-like groups can be seen in this plot. Although the SD-like samples had low $M_{\mathrm{s}}$ values and the signal to noise ratios of the SD-like samples were lower than those of the PSD-like samples, the signal to noise ratios $(>46)$ were large enough to distinguish these two groups.

\section{Stepwise AFD}

The stepwise AFD results are summarized in Fig. 6 and Additional file 1: Table S1. Magnetization of the samples with $M_{\mathrm{NRM}} / M_{\text {IRM }}$ values of $\sim 0.01, \sim 0.05$, and $\sim 0.1$ systematically decreased to the origin, as can be clearly seen in the orthogonal vector plots (Fig. $6 \mathrm{a}-\mathrm{c}$ ). On the other hand, the zircon crystals with $M_{\mathrm{NRM}} / M_{\text {IRM }}$ values of $\sim 1$ did not trend to the origin and showed unstable behavior during the AFD treatment (Fig. 6d). The normalized AFD curves are summarized in Fig. 7. The AFD curves are similar in shape for the samples with $M_{\mathrm{NRM}} / M_{\text {IRM }}$ values of $\sim 0.01, \sim 0.05$, and $\sim 0.1$, whereas dissimilar shapes were observed among the samples with $M_{\mathrm{NRM}} / M_{\text {IRM }}$ values of $\sim 1$. These results suggest that the main IRM carriers of the samples with $M_{\mathrm{NRM}} / M_{\text {IRM }}$ values of $\sim 0.01, \sim 0.05$, and $\sim 0.1$ and with $M_{\mathrm{NRM}} / M_{\text {IRM }}$ values of $\sim 1$ have different characteristics.

\section{Low-temperature magnetometry}

Results of the low-temperature remanence measurements are summarized in Fig. 8 and Additional file 1: Table S1. Most of the samples, except the two samples with $M_{\mathrm{NRM}} /$ $M_{\text {IRM }}$ values of $\sim 1$ (TNZ03-04-65 and TNZ03-15-57), showed pronounced remanence reductions at around $100-150 \mathrm{~K}$, which is suggestive of the Verwey transition for low-Ti titanomagnetite (Özdemir et al. 1993; Moskowitz et al. 1998). The smooth variation of remanences near $100-150 \mathrm{~K}$ indicated some impurities in magnetite grains. The curves also showed remanence reductions at $\sim 35$ and $\sim 50 \mathrm{~K}$, which may indicate the existence of magnetic minerals other than magnetite, such as pyrrhotite (Dekkers et al. 1989) and the rhombohedral phase of FeTi oxide (Ishikawa et al. 1985). The apparent transitions of $\sim 50 \mathrm{~K}$ were seen in most of the samples. If this transition indicates the rhombohedral phase of Fe-Ti oxide, it does not have remanent magnetization at room temperature. One sample (TNZ03-08-41) showed clear transition temperature $\sim 35 \mathrm{~K}$. If this transition indicates the pyrrhotite, it has remanent magnetization at room temperature and may affect paleointensity experiment. The intensity of FC remanence was larger than that of ZFC remanence, which is a characteristic behavior of SD and fine-grained PSD magnetite (Moscowitz et al. 1993; Kosterov 2003; Carter-Stiglitz et al. 2006), although the zircon crystals may contain magnetic minerals other than pure magnetite.

\section{Sample-selection criteria for future study of paleointensity experiments}

In this study, we carried out the systematic rock-magnetic measurements for the 1037 single zircon crystals using the standard magnetometers such as SQUID magnetometer, MPMS, and AGM. Combining the observed rockmagnetic parameters, we discuss sample-selection criteria for future study of paleointensity experiments using single zircon crystals.

The relationship between the $M_{\mathrm{NRM}}$ and $M_{\mathrm{IRM}}$ is shown in Fig. 9a. The samples that had $M_{\text {IRM }}$ smaller than the practical detection limit of the instrument used in this study (876 zircons) are considered to contain little or no magnetic minerals. The other zircon crystals contain enough magnetic minerals to be measured in the DC SQUID magnetometer. The zircon crystals that had $M_{\mathrm{IRM}} \geq 4 \times 10^{-12} \mathrm{Am}^{2}$ while $M_{\mathrm{NRM}}$ smaller than the detection limit (81 grains) are inappropriate for the paleomagnetic study. For the samples that had values of $M_{\mathrm{NRM}} \geq 4 \times 10^{-12} \mathrm{Am}^{2}$ and $M_{\mathrm{IRM}} \geq 4 \times 10^{-12} \mathrm{Am}^{2}$ (80 grains), the $M_{\mathrm{NRM}} / M_{\mathrm{IRM}}$ ratios were distributed in the range of 0.004-0.8, excepting one anomalous sample with $M_{\mathrm{NRM}} / M_{\mathrm{IRM}}$ value of $\sim 1.5$. This anomalously high $M_{\mathrm{NRM}} /$ $M_{\text {IRM }}$ value is considered to arise from strong anisotropy of the crystal. In the stepwise AFD curves of the IRM after LTD treatment, the samples with low $M_{\mathrm{NRM}} / M_{\mathrm{IRM}}$ value ( $\sim 0.01, \sim 0.05$, and $\sim 0.1)$ show the stable remanent magnetizations, while the samples with high $M_{\mathrm{NRM}} / M_{\text {IRM }}$ value $(\sim 1)$ show unstable behaviors. Thus, in terms of room temperature IRM properties, the samples with low $M_{\mathrm{NRM}} /$ $M_{\text {IRM }}$ value are desirable for paleointensity experiment.

Some large inclusions in the zircon crystals can be recognized from stereoscopic microscope observations (Fig. 2). The samples that had measureable IRM and NRM intensities tended to contain colored mineral inclusions (Fig. 2a-1 and Additional file 1: Table S1), while the samples that had both IRM and NRM intensities smaller than the detection limit rarely contain colored minerals (Fig. 2m-o). Tanzawa tonalites mainly consist of plagioclase, hornblende, quartz, and biotite with minor amounts of K-feldspar, chlorite, magnetite, ilmenite, \pm actinolite, \pm muscovite, \pm cummingtonite, and \pm tremolite (Suzuki et al. 2014). Note that the " \pm " denotes the way of description for minor minerals in the thinsection. In the petrology, the rock-forming minerals are described in descending order, and one thin-section sometimes contain the minor minerals but other times lack them even in the same rock sample. In such cases, the minor minerals would be represented as " \pm ". Assuming that inclusions are the same as the tonalite, the probable candidates of the colored minerals are biotite, magnetite, ilmenite, and amphiboles, and those of the transparent minerals are plagioclase and quartz. Moreover, from preliminary electron microscope observations, we 


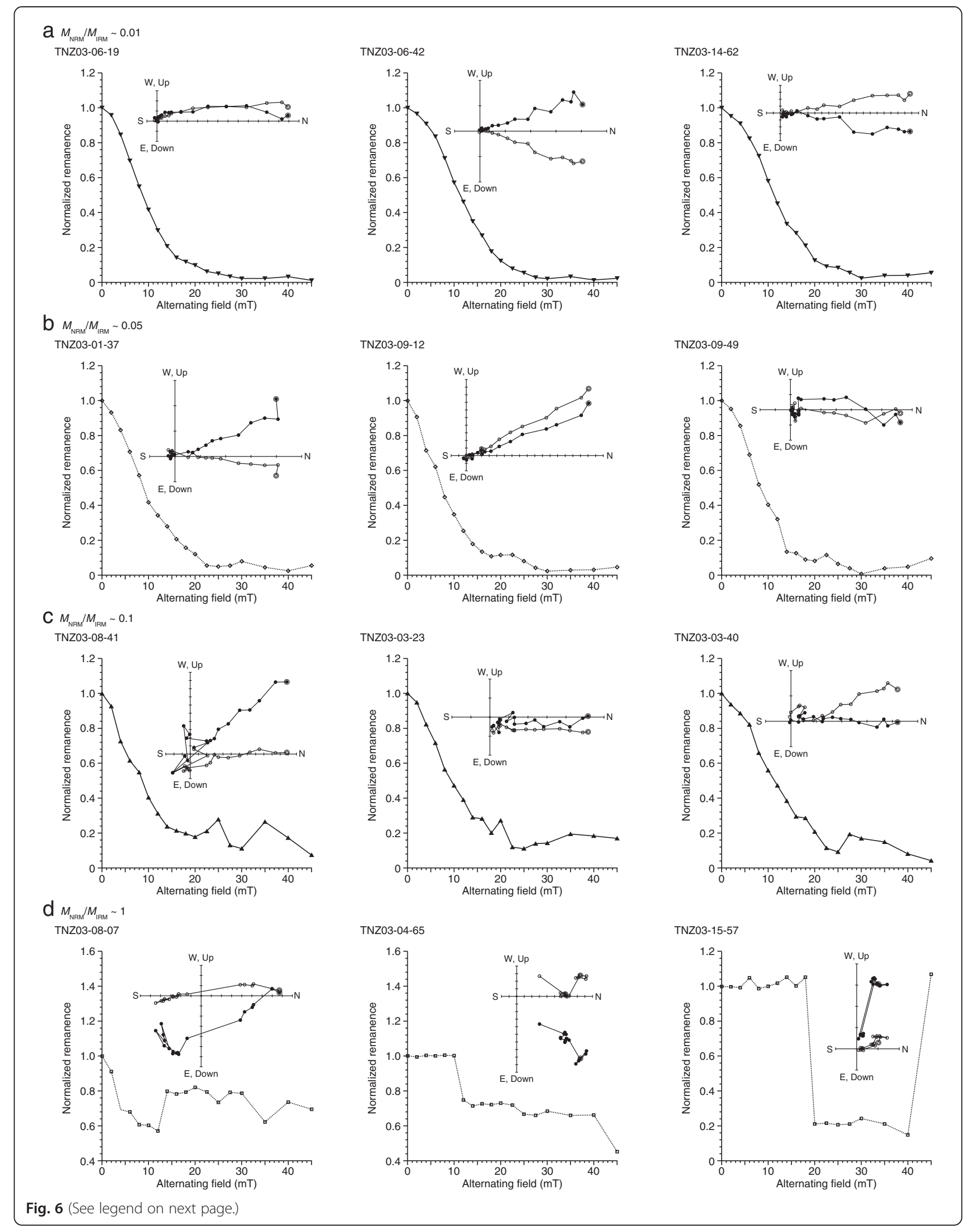


(See figure on previous page.)

Fig. 6 Results of stepwise AFD experiments for the selected zircon samples. Normalized remanence intensity is plotted as a function of applied peak AF field. The IRM was roughly imparted to the north direction. The samples which had $M_{\text {NRM }} / M_{\text {IRM }}$ values of $\mathbf{a} \sim 0.01, \mathbf{b} \sim 0.05$, $\mathbf{c} \sim 0.1$, and $\mathbf{d} \sim 1$ are shown as inverted triangle, diamond, triangle, and square symbols, respectively. (Insets) Orthogonal vector plots for stepwise AFD of IRMLTD. Closed and open symbols denote horizontal and vertical projections, respectively. Points corresponding to the remanence before AFD are shown as double circles

found that the samples with $M_{\mathrm{NRM}} / M_{\mathrm{IRM}}$ values of $\sim 1$ contain pyrrhotite crystals (TNZ03-04-65 and TNZ03-1557) and the TNZ03-08-07 sample contains both magnetite and pyrrhotite crystals. Relationships between the types of magnetic properties and mineral inclusions should be investigated by a future study of detailed microscopic observations.

The $M_{\mathrm{NRM}} / M_{\text {IRM }}$ ratios are plotted as a function of $B_{c}$ in Fig. 9b. In this plot, the values $M_{\mathrm{NRM}} / M_{\mathrm{IRM}}$ and $B_{\mathrm{c}}$ tend to indicate magnetic properties of main carrier for remanent magnetization and induced magnetization, respectively. Taking into account the result of microscope observations and low-temperature magnetometry, magnetic minerals contained in the samples with high $B_{\mathrm{c}}$ values $(>10 \mathrm{mT})$ are likely small numbers of pyrrhotite. If this is the case, main carriers for both remanent and induced magnetization were the small numbers of pyrrhotite, which is consistent with the stepwise change in remanence during AFD treatment and the high $B_{\mathrm{c}}$ values.

From the electron microscope observation and lowtemperature measurement, we found that TNZ03-08-41 $\left(B_{\mathrm{c}}=1.7 \mathrm{mT}, \quad M_{\mathrm{NRM}} / M_{\mathrm{IRM}}=0.1\right)$ and TNZ03-08-07 $\left(B_{\mathrm{C}}=6.3 \mathrm{mT}, M_{\mathrm{NRM}} / M_{\mathrm{IRM}}=0.7\right)$ contained both magnetite and pyrrhotite. The samples with low $B_{\mathrm{c}}$ values $(<10 \mathrm{mT})$ and high $M_{\mathrm{NRM}} / M_{\mathrm{IRM}}$ values $(>\sim 0.1)$ may

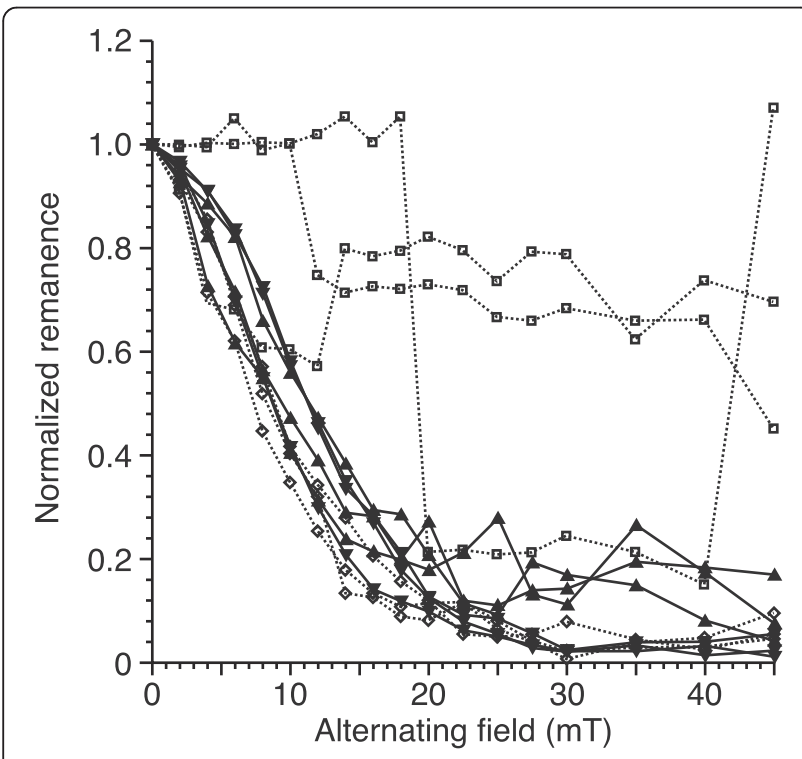

Fig. 7 Summary of the stepwise AFD curves for the selected zircon samples contain nearly pure magnetite and small numbers of pyrrhotite. The large induced magnetization of the magnetite over the small numbers of pyrrhotite dominates hysteresis properties, while the small numbers of pyrrhotite efficiently carry the remanent magnetization and dominates remanence properties.

The samples with low $B_{\mathrm{c}}$ values $(<10 \mathrm{mT})$ and low $M_{\mathrm{NRM}} / M_{\text {IRM }}$ values $(<\sim 0.1)$ showed (1) decrease in the IRM intensity after LTD treatment (Fig. 9c), (2) pronounced low-temperature remanence reduction at around 100-150 K (Fig. 8), (3) PSD-like $M_{\mathrm{rs}} / M_{\mathrm{s}}$ values, and (4) relatively stable behavior during stepwise AFD treatment (Fig. 6). The features (1) and (2) suggest the existence of titanomagnetite. Considering the slow cooling rate of the Azegamaru pluton (Fig. 1b), it is unlikely that Ti-rich titanomagnetite existing in zircon crystals, and thus, the main magnetic mineral of these samples is nearly pure magnetite with PSD grain sizes.

In the present study, we did not measure the magnetic anisotropy. Unlike feldspars or pyroxenes, there is no apparent reason to believe that exsolution should be a common process in zircon. Therefore, anisotropy is not expected, but it could be present if the magnetization is dominated by small numbers of inclusions such as the pyrrhotite-bearing samples (high $B_{\mathrm{c}}$ values of $>10 \mathrm{mT}$ or high $M_{\mathrm{NRM}} / M_{\text {IRM }}$ values of $>\sim 0.1$ ).

In the case that the samples had high $B_{\mathrm{c}}$ values (>10 $\mathrm{mT}$ ) or high $M_{\mathrm{NRM}} / M_{\mathrm{IRM}}$ values (> 0.1), main remanence carriers are probably pyrrhotite, and these samples are inappropriate for the paleointensity study. In the case that the samples had low $B_{\mathrm{c}}$ values $(<10 \mathrm{mT})$ and low $M_{\mathrm{NRM}} / M_{\mathrm{IRM}}$ values $(<\sim 0.1)$, the main remanence carrier seems to be nearly pure magnetite with PSD grain sizes. These samples showed the moderate LTD memories of IRM (50-70 \%, Fig. 9c) and relatively stable behavior during stepwise AFD treatment (Fig. 6). The 50 $\mu \mathrm{T}$-TRM/SIRM ratios for pure PSD magnetite ranged from 0.006 to 0.1 (Figure $1 \mathrm{~b}$ in $\mathrm{Yu} 2010$ ); the NRMs of the sample with $M_{\mathrm{NRM}} / M_{\text {IRM }}$ values of $<\sim 0.1$ may have a TRM origin. Thus, the samples had low $B_{\mathrm{c}}$ values $(<10 \mathrm{mT})$ and low $M_{\mathrm{NRM}} / M_{\mathrm{IRM}}$ values $(<\sim 0.1)$ are expected to be appropriate for the paleointensity study. The threshold value of $M_{\mathrm{NRM}} / M_{\mathrm{IRM}} \sim 0.1$ is tentative, and it would be better to select the sample with sufficiently small $M_{\mathrm{NRM}} / M_{\mathrm{IRM}}$ values such as $<\sim 0.05$. In addition, it is worth noting that the data shown here are much more complicated than other single silicate results 


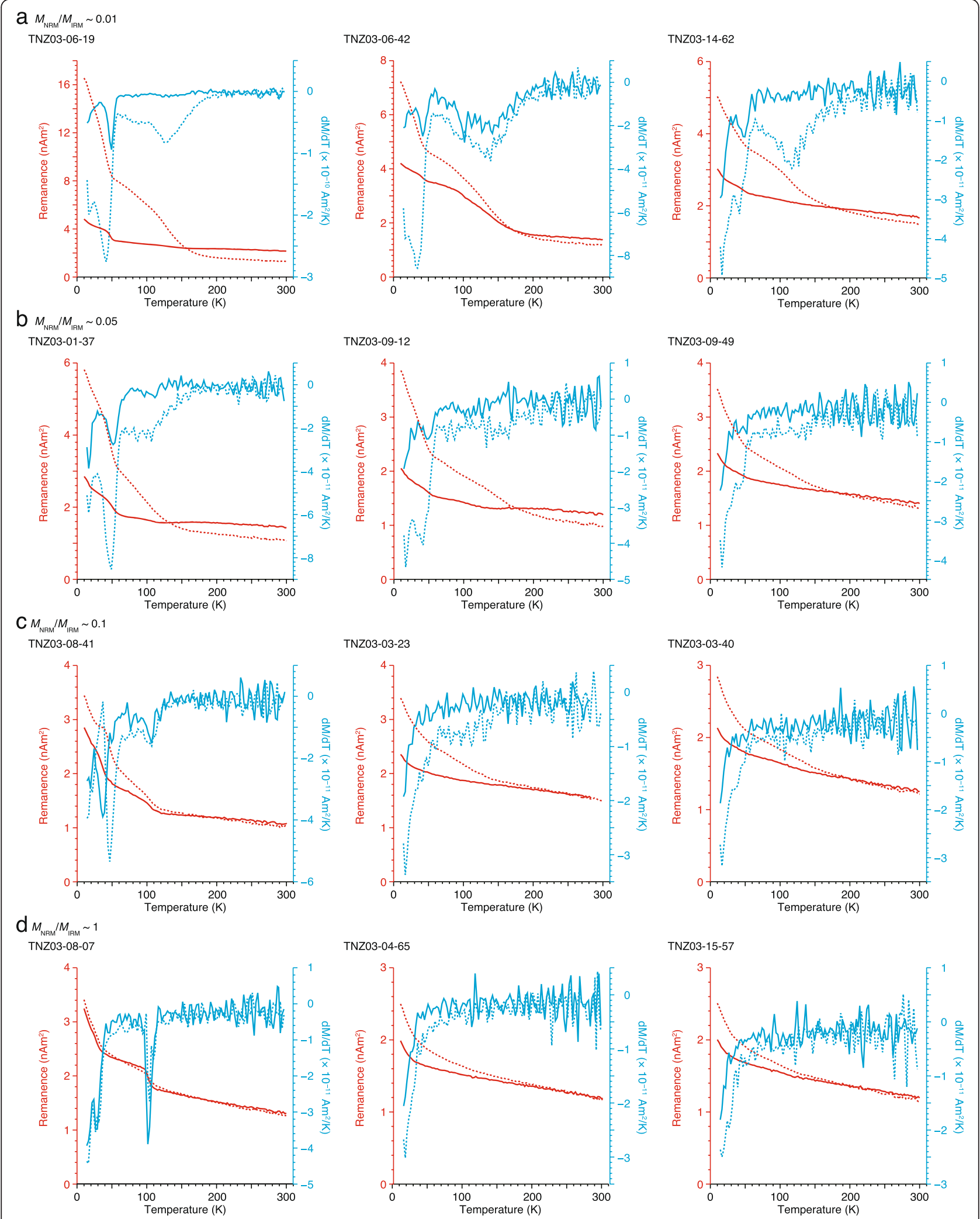

Fig. 8 Results of low-temperature remanence measurements for the selected zircon samples. The ZFC remanence and FC remanence curves are shown with red color as bold and dot lines, respectively. Temperature derivatives of the ZFC remanence and FC remanence curves are shown with blue color as bold and dotted lines, respectively 


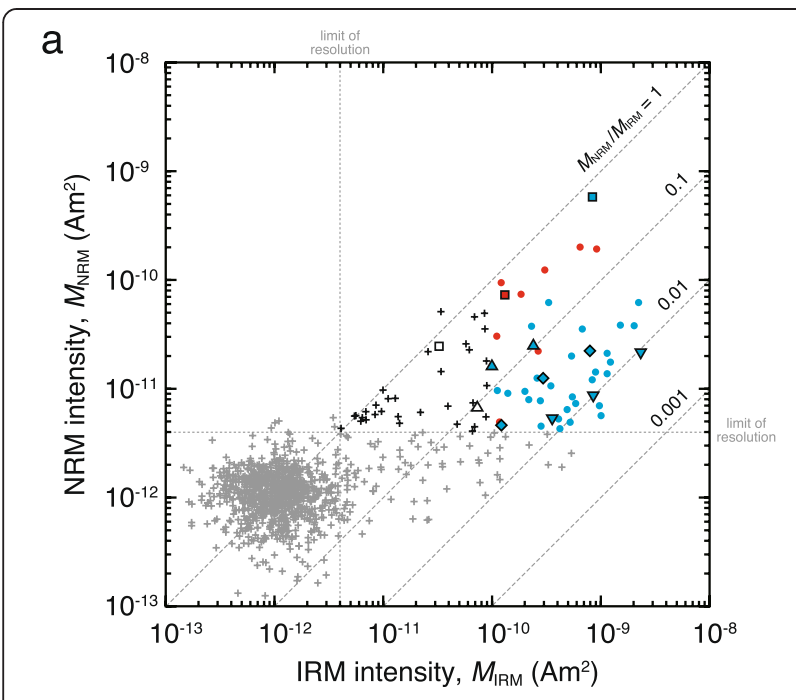

b

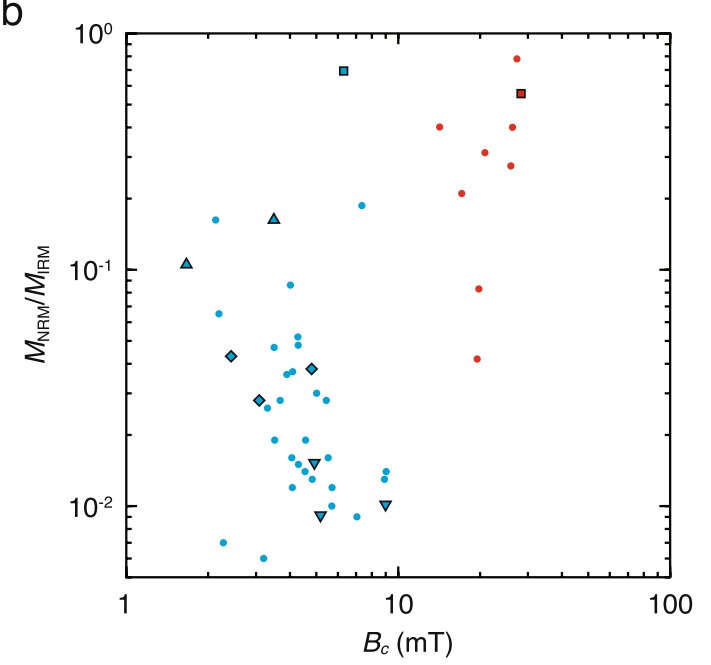

C

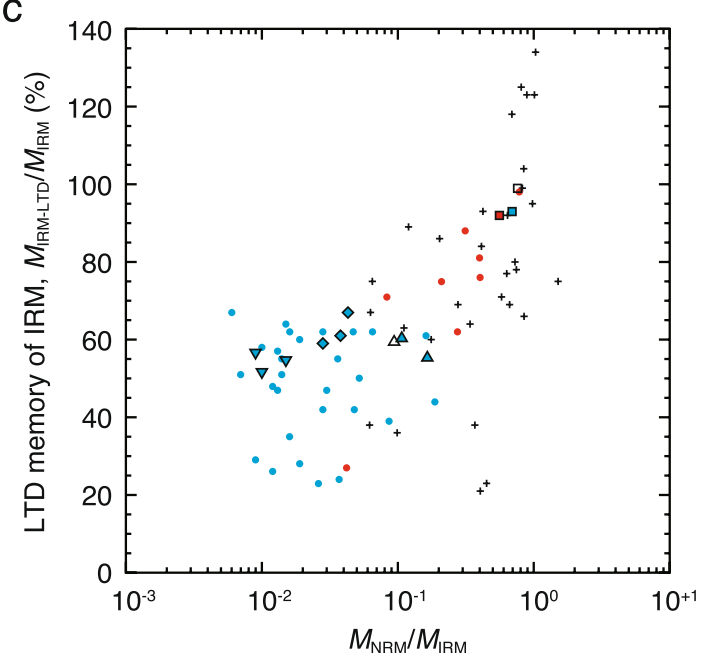

Fig. 9 a The NRM intensity is plotted as a function of the IRM intensity. Diagonal lines indicate IRM/NRM ratios of 1, 0.1, 0.01, and 0.001 , respectively. Vertical and horizontal grey lines indicate $4 \times$ $10^{-12} \mathrm{Am}^{2}$ intensity lines (detection limit). The sample with $M_{\mathrm{IRM}}<$ $4 \times 10^{-10} \mathrm{Am}^{2}$ or $M_{\mathrm{NRM}}<4 \times 10^{-12} \mathrm{Am}^{2}$ are shown as grey symbols. b The NRM/IRM ratio is plotted as a function of $B_{c}$. $\mathbf{c}$ The LTD memory of IRM is plotted as a function of the NRM/IRM ratio. The SD- and PSD-like samples are plotted as red and blue symbols, respectively (see Fig. 5). The selected samples are shown as inverted triangle, diamond, triangle, and square symbols (see Fig. 6)

so far reported, and thus, rock-magnetic investigations with large number of crystals similar to this study would be necessary to provide solid ground for single silicate crystal paleomagnetism, including feldspar or quartz.

\section{TRM experiments-implication for paleointensity experiment}

Toward the establishment of a reliable paleointensity method using single zircon crystal, we selected 13 zircon crystals with $M_{\mathrm{NRM}} / M_{\text {IRM }}$ values of $0.01-0.05$ and low $B_{\mathrm{c}}$ values of $<10 \mathrm{mT}$ and used these in a TRM acquisition experiment. The TRM was imparted by heating crystals to $610{ }^{\circ} \mathrm{C}$ for $15 \mathrm{~min}$ and cooling them back to room temperature with a $60-\mu \mathrm{T}$ DC field. The heating procedures were conducted in a vacuum $(<10 \mathrm{~Pa})$ with a TDS-1 thermal demagnetizer (Natsuhara-Giken). One of the 13 crystals broke during the heating procedure. The TRM intensities $\left(M_{\text {TRM }}\right)$ of the remaining 12 crystals were measured using the model 755 cryogenic magnetometer at CMCR, Kochi University.

Results of the TRM experiment are summarized in Fig. 10 and Additional file 1: Table S2. The NRM/TRM ratios varied from 0.2 to 2.2 (Fig. 10a), indicating that the NRM intensity is comparable to the TRM intensity. For the crystals with $M_{\mathrm{TRM}} \geq 10 \mathrm{pAm}^{2}$, an average of $M_{\mathrm{NRM}} / M_{\mathrm{TRM}}$ values was 0.69 . This corresponds to $41 \mu \mathrm{T}$ if we roughly estimate possible paleointensity because we imparted TRM with a 60- $\mu$ T DC field (Fig. 10b).

Considering an average virtual axial dipole moment of $3.64 \pm 2.10 \times 10^{22} \mathrm{Am}^{2}$ for the last $5 \mathrm{Myr}$ concluded by Yamamoto and Tsunakawa (2005), the geomagnetic field intensity at the Tanzawa tonalitic pluton $\left(35^{\circ} 26^{\prime} \mathrm{N}\right)$ has been estimated to be $8-31 \mu \mathrm{T}$ for that period. This is comparable to the rough estimate of $41 \mu \mathrm{T}$ in the present study, which suggests that the selected zircon crystals hold NRMs with a TRM origin, while (thermo) chemical remanent magnetization or (thermo) viscous remanent magnetization may well be plausible origins of NRM in the zircon crystals. Moreover, the slow cooling rate of the Azegamaru pluton $\left(\sim 658{ }^{\circ} \mathrm{C} / \mathrm{Myr}\right)$ may affect the paleointensity estimate. The effect of cooling rate on TRM intensity is dependent on the grain size of magnetite. $\mathrm{Yu}$ (2011) tested the practical effect of cooling rate on the magnitude of TRM using natural and synthetic magnetite. 

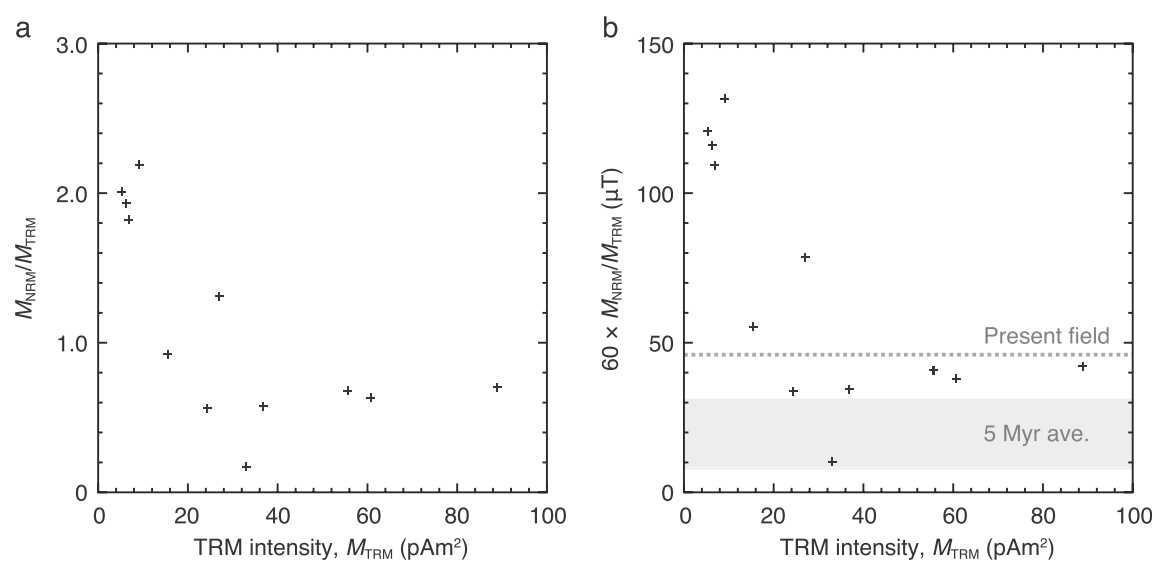

Fig. 10 Results of TRM experiment. a The NRM/TRM ratio is plotted as a function of TRM intensity. $\mathbf{b}$ The $60 \times$ NRM/TRM value is plotted as a function of TRM intensity. Present and 5 Myr average geomagnetic field intensity of Tanzawa are indicated as grey line and band, respectively

As the results, TRM intensity of SD samples decrease as the cooling rate increases, while MD samples showed an opposite trend. TRM intensity of PSD samples remain almost unchanged as the cooling rate decreases. As the zircon crystals used in the TRM experiment showed the PSD-like hysteresis parameters which were close to the PSD/MD boundary (Fig. 5e and Additional file 1: Table S2), the roughly estimated paleointensity value of $41 \mu \mathrm{T}$ was considered to be lower bound.

Considering the thermal history of the Azegamaru pluton (Fig. 1b), it is expected that a future study using the zircon crystals with low $B_{\mathrm{c}}$ values $(<10 \mathrm{mT})$ and low $M_{\text {NRM }} / M_{\text {IRM }}$ values $(<\sim 0.1)$ could provide reliable paleointensity data of the Tanzawa at $\sim 3-4$ Ma. Note that, for the future paleointensity experiment using single zircon crystal, it would be necessary to conduct more detailed analyses of zircon crystals such as (a) thermomagnetic analysis, (b) checking stability against heating, (c) direct observation of inclusions, and (d) NRM directional consistency tests using in-situ zircons in the tonalite.

\section{Conclusions}

In this study, we conducted a suite of rock-magnetic experiments for 1037 single zircon crystals sampled from the Nakagawa River, which crosses the Tanzawa tonalitic pluton in central Japan. The zircon crystals originated from the Azegamaru pluton, where the thermal history is clearly known. The IRM intensities for 876 zircon crystals were smaller than the practical detection limit of the instrument used in this study $\left(\sim 4 \times 10^{-12} \mathrm{Am}^{2}\right)$; these crystals contain no or only minute quantities of ferromagnetic minerals. The other zircon crystals contain enough magnetic minerals to be measured in the DC SQUID magnetometer. For the samples that had values of $M_{\mathrm{NRM}} \geq 4 \times 10^{-12} \mathrm{Am}^{2}$ and $M_{\mathrm{IRM}} \geq 4 \times 10^{-12} \mathrm{Am}^{2}$, the low-temperature magnetometry and microscopic observation revealed that the zircon crystals contained magnetite and pyrrhotite. Combining the rock-magnetic parameter, we proposed the sample-selection criteria for future study of paleointensity experiments using single zircon crystals. In the case that the samples had high $B_{\mathrm{c}}$ values $(>10 \mathrm{mT})$ or high $M_{\mathrm{NRM}} / M_{\mathrm{IRM}}$ values (> 0.1), main remanence carriers are considered to be pyrrhotite, and these samples are inappropriate for the paleointensity study. In the case that the samples had low $B_{\mathrm{c}}$ values $(<10 \mathrm{mT})$ and low $M_{\mathrm{NRM}} / M_{\text {IRM }}$ values $(<\sim 0.1)$, the main remanence carrier seems to be nearly pure magnetite with PSD grain sizes, and these samples are expected to be appropriate for the paleointensity study. The TRM acquisition experiments were also carried out on 12 of the zircon crystals that satisfied the above criteria $\left(B_{\mathrm{c}}<10 \mathrm{mT}\right.$ and $M_{\mathrm{NRM}} / M_{\mathrm{IRM}}<$ $\sim 0.1$ ). The ratios of NRM to TRM varied in the $0-2$ range, thus indicating that the NRM intensity is comparable with that of TRM. The rough estimation of paleointensity using the bulk NRM/TRM ratio for the strong TRM sample showed a field intensity that was consistent with the geomagnetic field intensity at the Tanzawa tonalitic pluton for the last 5 Myr. Overall, the results from this study suggest that single zircon crystals of the Tanzawa tonalite would be applicable to paleointensity experiments.

\section{Additional file}

Additional file 1: Supplemental Figures and Tables. Figure S1. Photo images of the sample holder. Figure S2. An example of the sample holder measurements. The holder moments were shown in orthogonal vector plots. Figure S3. Magnetic hysteresis curves for the P2 AGM transducer probe after a diamagnetic/paramagnetic correction. Figure S4. Effect of the $\mathrm{HCl}$ treatment. The intensity of IRM imparted with a field of $140 \mathrm{mT}$ is plotted as a function of the $\mathrm{HCl}$ treatment time. Table S1. Summary of the AFD experiment samples. Table S2. Summary of the TRM experiment samples. (PDF $4161 \mathrm{~kb}$ )

\section{Competing interests}

The authors declare that they have no competing interests. 


\section{Authors' contributions}

MS, SY, and YO conducted the geological survey. MS conducted the magnetic measurement. All contributed to discussion and wrote the manuscript. All authors read and approved the final manuscript.

\section{Acknowledgements}

We thank Tetsu Kogiso for help with XRF experiments at Kyoto University. This study was performed under the cooperative research program of Center for Advanced Marine Core Research (CMCR), Kochi University <Accept No. 12B040, 13A012, 13B011, 14A007, and 14B005>. This work was supported by JSPS Grant-in-Aid for Challenging Exploratory Research No. 26610142.

\section{Author details}

${ }^{1}$ Geological Survey of Japan, National Institute of Advanced Industrial Science and Technology, 1-1-1 Higashi, Tsukuba 305-8567, Japan. ${ }^{2}$ Department of Environmental Changes, Faculty of Social and Cultural Studies, Kyushu University, 744 Motooka, Nishi-ku, Fukuoka 819-0395, Japan. ${ }^{3}$ Department of Earth and Astronomy, Graduate School of Arts and Sciences, The University of Tokyo, 3-8-1 Komaba, Meguro-ku, Tokyo 153-8902, Japan. ${ }^{4}$ Center for Advanced Marine Core Research, Kochi University, B200 Monobe, Kochi 783-8502, Japan. ${ }^{5}$ Department of Earth and Planetary Sciences, Tokyo Institute of Technology, 2-12-1 Ookayama, Meguro-ku, Tokyo 152-8550, Japan. ${ }^{6}$ Earth-Life Science Institute, Tokyo Institute of Technology, 2-12-1 Ookayama, Meguro-ku, Tokyo 152-8550, Japan.

\section{Received: 11 May 2015 Accepted: 27 August 2015}

\section{Published online: 15 September 2015}

\section{References}

Carter-Stiglitz B, Moskowitz B, Solheid P, Berquó TS, Jackson M, Kosterov A (2006) Low-temperature magnetic behavior of multidomain titanomagnetites: TM0, TM16, and TM35. J Geophys Res 111:B12S05

Day R, Fuller M, Schmidt V (1977) Hysteresis properties of titanomagnetites: grain-size and compositional dependence. Phys Earth Planet Inter 13:260-267

Dekkers MJ, Mattéi JL, Fillion G, Rochette P (1989) Grain-size dependence of the magnetic behavior of pyrrhotite during its low-temperature transition at 34 K. Geophys Res Lett 16:855-858

Dunlop SD (2002) Theory and application of the Day plot $\left(M_{r s} / M_{s} v s . H_{c r} / H_{c}\right) 1$. Theoretical curves and tests using titanomagnetite data. J Geophys Res 107(B3):EPM 4-1-EPM 4-22

Heider F, Dunlop DJ, Soffel HC (1992) Low-temperature and alternating field demagnetization of saturation remanence and thermoremanence in magnetite grains (0.037 um to 5 mm). J Geophys Res 97(B6):9371-9381

Ishihara S, Kanaya H, Terashima S (1976) Genesis of the Neogene granitoids in the Fossa Magna region in Japan. Marine Sci Monthly 8:523-528

Ishihara S, Matsuhisa Y (1999) Oxygen isotopic constraints on the geneses of the Miocene Outer Zone granitoids in Japan. Lithos 46:523-534

Ishikawa Y, Saito N, Arai M, Watanabe Y, Takei H (1985) A New Oxide Spin Glass System of (1-x) $\mathrm{FeTiO}_{3}-\mathrm{xFe} \mathrm{O}_{3}$. I. Magnetic Properties. J Phys Soc Jpn 54:312-325

Kawate S, Arima M (1998) Petrogenesis of the Tanzawa plutonic complex, central Japan: exposed felsic middle crust of the Izu-Bonin-Mariana arc. Island Arc 7:342-358

Kawate S, Fujimaki H (1996) Strontium isotope composition of the Tanzawa plutonic rocks in the Izu-Bonin arc. Japan Earth and Planetary Science Joint Meeting, Abstracts, Osaka, Japan, 703.

Kosterov A (2003) Low-temperature magnetization and AC susceptibility of magnetite: effect of thermomagnetic history. Geophys J Int 154:58-71

Lewis RR, Senftle FE (1966) The source of ferromagnetism in zircon. Am Mineral $51: 1467-1475$

Matsuda T (1978) Collision of Izu-Bonin arc with central Honshu. Cenozoic tectonics of the Fossa Magna, Japan. J Phys Earth 26:S409-S421

Moskowitz BM, Frankel RB, Bazylinski DA (1993) Rock magnetic criteria for the detection of biogenic magnetite. Earth Planet Sci Lett 120(3):283-300

Moskowitz BM, Jackson M, Kissel C (1998) Low-temperature magnetic behavior of titanomagnetites. Earth Planet Sci Lett 157:141-149

Muxworthy AR, Evans ME (2012) Micromagnetics and magnetomineralogy of ultrafine magnetite inclusions in the Modipe Gabbro. Geochem Geophys Geosyst 14:921-928
Niitsuma S, Niitsuma N, Saito K (2003) Evolution of the Komiji Syncline in the North Fossa Magna, central Japan: Paleomagnetic and K-Ar age insights. Island Arc 12:310-323

Özdemir Ö, Dunlop DJ, Moskowitz BM (1993) The effect of oxidation on the Verwey transition in magnetite. Geophys Res Lett 20:1671-1674

Rudnick RL, Fountain DM (1995) Nature and composition of the continental crust: a lower crustal perspective. Rev Geophys 33:267-309

Suyehiro K, Takahashi N, Ariie Y, Yokoi Y, Hino R, Shinohara M, Kanazawa T, Hirata N, Tokuyama H, Taira A (1996) Continental crust, crustal underplating, and low-q upper mantle beneath an oceanic island arc. Science 272:390-392

Suzuki K, Yamamoto S, Sawaki Y, Aoki K, Omori S, Kon Y, Hirata T, Li Y, Takaya Y, Fujinaga K, Kato Y, Maruyama S (2014) Zircon U-Pb dating from the mafic enclaves in the Tanzawa Tonalitic Pluton, Japan: Implications for arc history and formation age of the lower-crust. Lithos 196-197:301-320

Takahashi N, Kodaira S, Klemperer SL, Tatsumi Y, Kaneda Y, Suyehiro K (2007) Crustal structure and evolution of the Mariana intra-oceanic island arc. Geology 35:203-206

Takita R (1974) Petrography and plutonic history of the Tanzawa tonalite complex. Journal of the Geological Society of Japan 80:505-23 (in Japanese with English abstract)

Tamura Y, Ishizuka O, Aoike K, Kawate S, Kawabata H, Chang Q, Saito S, Tatsumi Y, Arima M, Takahashi M, Kanamaru T, Kodaira S, Fiske RS (2010) Missing oligocene crust of the Izu-Bonin arc: consumed or rejuvenated during collision? J Petrology 51:823-846

Tani K, Dunkley DJ, Kimura J, Wysoczanski RJ, Yamada K, Tatsumi Y (2010) Syncollisional rapid granitic magma formation in an arc-arc collision zone: evidence from the Tanzawa plutonic complex, Japan. Geology 38:215-218

Tarduno JA, Blackman EG, Mamajek EE (2014) Detecting the oldest geodynamo and attendant shielding from the solar wind: Implications for habitability. Phys Earth Planet Int 223:68-87

Tarduno JA, Cottrell RD, Davis WJ, Nimmo F, Bono RK (2015) A Hadean to Paleoarchean geodynamo recorded by single zircon crystals. Science 349:521-524

Tarduno JA, Cottrell RD, Nimmo F, Hopkins J, Voronov J, Erickson A, Blackman E, Scott ERD, McKinley R (2012) Evidence for a dynamo in the main group pallasite parent body. Science 338:939-942

Tarduno JA, Cottrell RD, Smirnov AV (2006) The paleomagnetism of single silicate crystals: recording geomagnetic field strength during mixed polarity intervals, superchrons, and inner core growth. Rev Geophys 44:RG1002

Tarduno JA, Cottrell RD, Watkeys MK, Hofmann A, Doubrovine PV, Mamajek EE, Liu D, Sibeck DG, Neukirch LP, Usui Y (2010) Geodynamo, solar wind, and magnetopause 3.4 to 3.45 billion years ago. Sience 327:1238-1240

Tauxe L, Bertram HN, Seberino C (2002) Physical interpretation of hysteresis loops: micromagnetic modeling of fine particle magnetite. Geochem Geophys Geosyst 3(10):1055

Yamada K, Tagami T (2008) Postcollisional exhumation history of the Tanzawa Tonalite Complex, inferred from (U-Th)/He thermochronology and fission track analysis. J Geophys Res 113:B03402

Yamamoto S, Nakajima J, Hasegawa A, Maruyama S (2009) Izu-Bonin arc subduction under the Honshu island, Japan: evidence from geological and seismological aspect. Gondwana Res 16:572-580

Yamamoto Y, Tsunakawa H (2005) Geomagnetic field intensity during the last 5 Myr: LTD-DHT Shaw palaeointensities from volcanic rocks of the Society Islands, French Polynesia. Geophys J Int 162:79-114

Yu Y (2010) Paleointensity determination using anhysteretic remanence and saturation isothermal remanence. Geochem Geophys Geosyst 11:Q02Z12

Yu Y (2011) Importance of cooling rate dependence of thermoremanence in paleointensity determination. J Geophys Res 116, B09101 